\title{
COMPUTERIZED HEAT-TREATMENT IN A ZIMBABWEAN FACTORY
}

\author{
M. Collier and E. Bhero \\ Department of Electronic Engineering \\ National University of Science \& Technology \\ Box AC939, Ascot, \\ Bulawayo, Zimbabwe \\ mike@collier.icon.co.zw \\ itadmin@boltnail.com
}

\begin{abstract}
In the context of Zimbabwe's current economic problems, parts of the manufacturing industry are turning their attention to the possibility of utilising local design talent in upgrading their manufacturing plants. This paper describes a project undertaken by the National University of Science and Technology to convert the heat-treatment process in a major manufacturing plant from semi-manual to a computerized one. The system comprises microcontroller connection to the furnaces and sensors, and communicates with a central computer on which software for a windowed user-interface is hosted. Experimental results for the system are presented, and a strategy for other companies in the same predicament is proposed.
\end{abstract}

\section{Introduction}

Zimbabwe's industry is undergoing a major shift, owing to the current political, economic and social changes taking place in the country. The strong manufacturing base developed over the last thirty years is under pressure because of lack of foreign currency and import restrictions. At the same time there is an urgent need to maintain, upgrade and improve the plant and information systems. As a result, attention is being given to greater utilisation of local expertise in the development of more sophisticated manufacturing methods, and companies are turning to local academic and professional organisations for the necessary innovation [1]. One area where this trend is particularly apt is the application of microcontrollers in production systems [2].

The project described in this paper concerns a company which is a well-established manufacturer of precision bolts, nails and screws, with a sizeable plant in Bulawayo. The operation involved improving the heat-treatment process by computerization of the furnace temperature control operations. The analysis, design, installation and testing were carried out by members of the Department of Electronic Engineering at the National University of Science and Technology in Bulawayo.

\section{Details of the Process}

\subsection{The original system}

The company, Bolt Manufacturers Africa, is a major supplier of ferrous fasteners for the 
construction industry in Zimbabwe. The work-force totals 270 , and the plant produces an annual output of 80,000 tons of nails, 4000 tons of bolts, 600 tons of roofing fasteners and 700 tons of rock-fixing bolts. Surface hardness is of major importance in many of these items, and the finishing process plays a significant part in maintaining product quality.

The heat-treatment workshop contains twelve furnaces for handling various types of steel products. Five of these are salt-baths which are heated by passage of current through the solution. For the past decade these have been semi-manually controlled by two Commander 50 control units which display the temperature of the furnaces derived from thermocouple readings. Each of these units can control only one salt-bath furnace at a time. Figure 1 shows the connection of one of these units to a furnace, where readings from the thermocouples in the solution are used to control the heating currents. The other furnaces are of either the box-oven or glow-bar types and use electrical heaters each consuming $22 \mathrm{~kW}$ of power. These furnaces have capacities ranging from $30,000 \mathrm{~cm}^{3}$ to $60,000 \mathrm{~cm}^{3}$, and have been operated by means of simple analogue controllers.

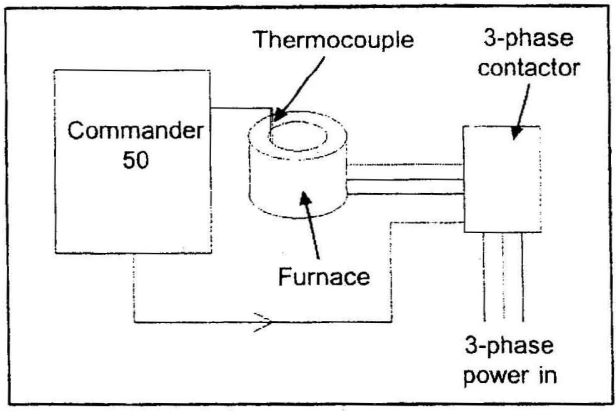

Figure 1: Commander 50 control system

\subsection{Reasons for upgrading}

For a number of years the heat-treatment department had been plagued by problems with the effective control of their furnaces, arising from the following problems:-

1. Large deviations of temperature from the specified set-points, resulting in warping and cracking of materials.

2. The difficulty ui setting the main Commander 50 controller with consistent accuracy, since the operators were required to adjust in excess of a dozen parameters before proper operation.

3. The uncertainties inherent in the use of the existing analogue controller, which did not include a temperature display panel, thus causing the control to be largely a mixture of experience and guesswork.

4. The maintenance and calibration of both the Commander 50 and analogue equipment, which was costly and often required the services of an expert from outside the company if not the country.

\section{The New Computer Control Configuration}

The aim of the project was to achieve a degree of integrated furnace control [3] by moving the controlling station for the heat-treatment process out of the noisy, smoky and somewhat hazardous environment of the factory floor. Therefore the main computer has been installed in a supervisor's room overlooking the furnaces, but insulated in terms of noise and temperature from the main workshop. The basic concept is that the computer is used to provide a display of all the furnace temperatures, and to comprise the operator's interface for 
adjustment of furnaces and setting up of complete treatment cycles. The computer communicates with an 8031 microcontroller [4] [5] [6] which monitors and actuates all the furnaces in the workshop. Since it is unusual for all twelve fumaces to be in simultaneous operation, the computerization is applied to only four of these, with provision for switching so that any four can be operated at one time.

The use of microcontrollers in this design, rather that discrete circuits [7] or programmable logic controllers, was determined by the expertise and experience of the design team.

A further benefit of the new arrangement is that the control computer can be accessed through the company's Intranet, enabling any staff member to observe the current state and recent history of the furnaces in the heat-treatment department.

\section{The Hardware Design and Installation}

The basic form of the new system is shown in Figure 2, in which the microcontroller receives inputs from the four thermocouples, and sends control signals to the actuators which operate the heaters in the furnaces [8].

The existing thermocouples are retained and connected directly to the amplifier circuits which give an overall voltage gain in the region of 300 before input to the programmable Analogue-to-Digital converter. This A/D converter has eight inputs which are individually addressable, and uses a Peripheral Interface Adapter to interface to the microcontroller. On the actuator side the existing 3-phase contactors are used to energise the heaters in the furnaces, with the control signals for these being derived from the microcontroller outputs through a cascade of transistor switches, $12 \mathrm{~V}$ and $220 \mathrm{~V}$ relays.

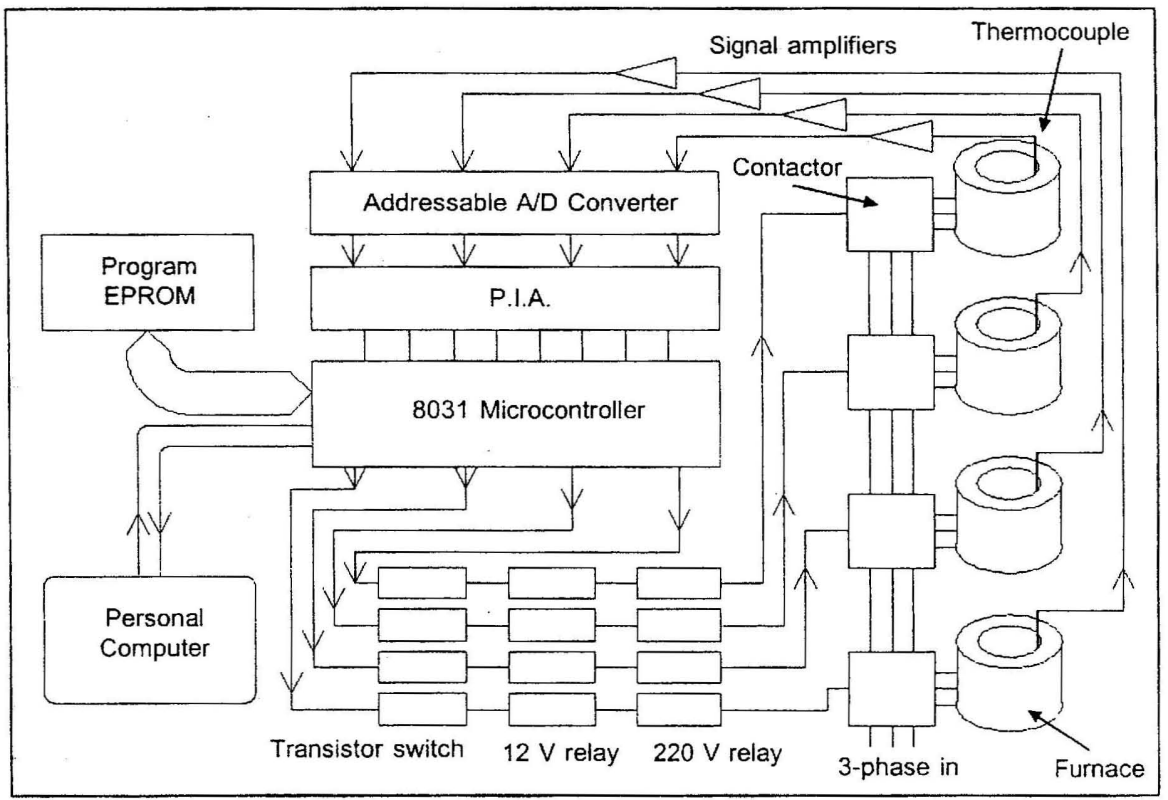

Figure 2: The basic arrangement of the new control system 


\section{Software Design}

\subsection{Partitioning the process}

In common with many real-time computer-based control systems, the data processing is carried out by two distinct hardware units. The personal computer executes high-level operations, while the microcontroller handles the low-level activities associated with the sensing and control of the factory equipment. The data-flow paths between the operator and furnaces are shown in Figure 3.

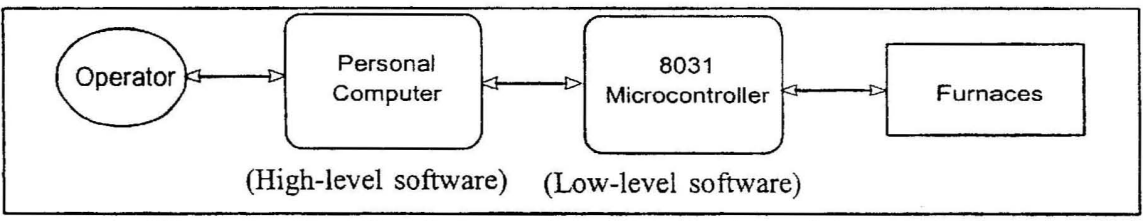

Figure 3: Data flow between the various sections of the system

An important aspect of the early stages of software design is the partitioning of the process into high and low-level functions, and the allocation of these to the appropriate processing units. The basic philosophy used in this project is to allocate all user-interface operations to the personal computer, and to implement bit-level logic for the interface to the furnaces in the microcontroller. Additionally, the execution of the heat-treatment cycle algorithms is carried out in the computer to accommodate the sizeable look-up tables required for the different classes of material under treatment.

To enable RS232 serial communication between the computer and the microcontroller, both need to have serial driver routines within their software. Since the serial transmission rate is relatively slow, the calculation of temperature values is undertaken in the microcontroller, and the results are transmitted as ASCII characters to the computer.

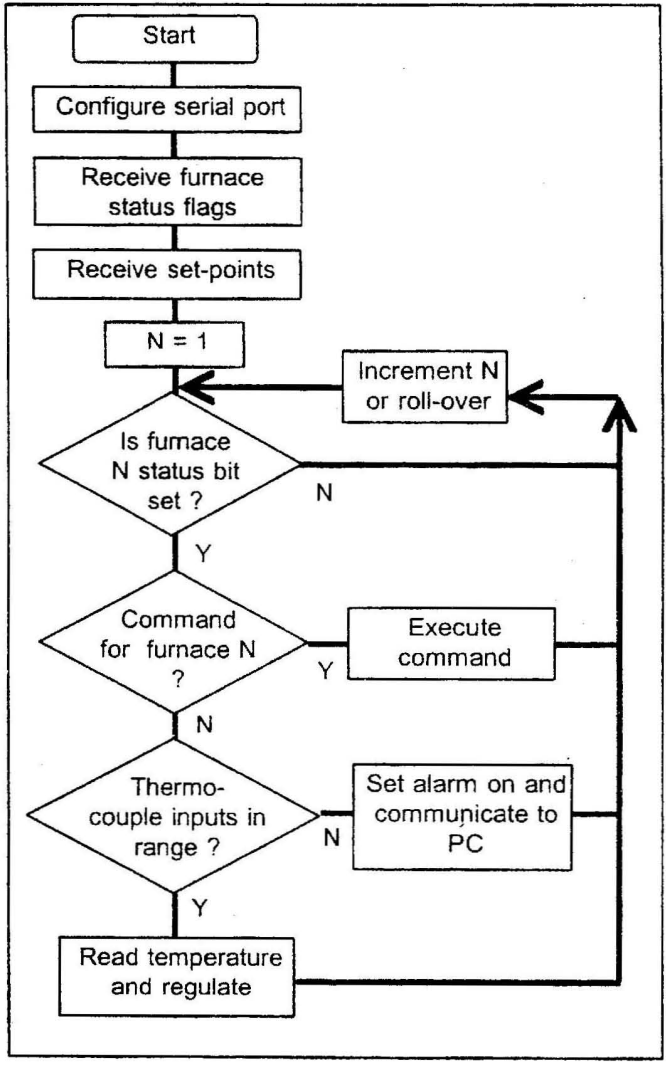

Figure 4: Flowchart for low-level routine in microcontroller 


\subsection{Microcontroller program}

The ports of the 8031 serve four purposes:-

1. To receive the binary representations of the temperatures from the $A / D$ converter.

2. To transmit the temperature values in serial format to the computer.

3. To receive control signals from the computer.

4. To output the control signals as binary data to the furnace actuators.

Therefore the assembly language program in the microcontroller takes the form of a routine which continuously polls the serial input from the computer and the parallel inputs from the four channels of the $\mathrm{A} / \mathrm{D}$ converter (via the Peripheral Interface Adapter) [9]. In this way each furnace is given attention sequentially.

The program is written in ASM51 assembly language, and the form of the flow chart is shown in Figure 4.

\subsection{Host computer software}

The control software is programmed in Power-C with the Mix Windows Toolkit, to produce executables which are portable between machines with operating systems ranging from MSDOS to Windows 2000. Such flexibility is an important requirement in a country where there is a great range of computer equipment on the industrial scene.

The Communications Software comprises a standard RS232 transmit/receive algorithm which

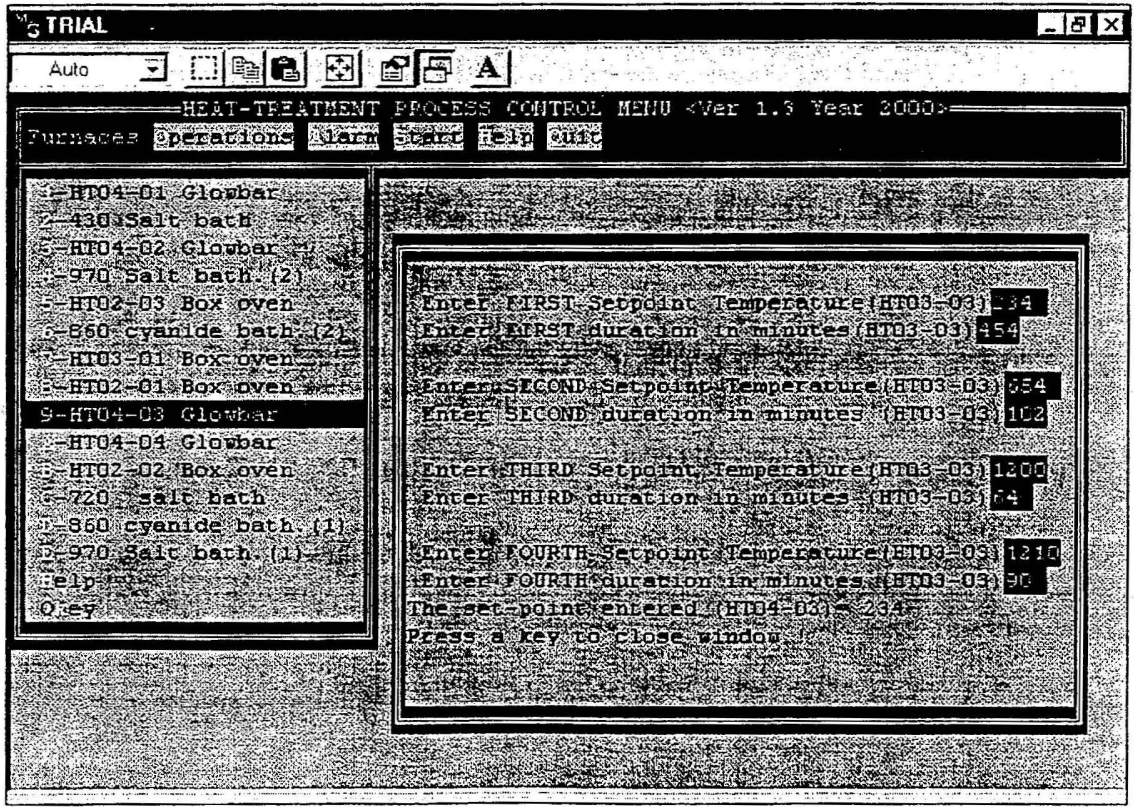

Figure 5: User interface showing windows for setting system control parameters 
accesses the registers of the UART chip in the computer directly, and provides handshaking between microcontroller and computer by XON-XOFF operation.

The User Interface is entirely windowed, and operates by selection from menus, or by entry of numerical values in dialogue boxes. Figure 5 shows the menu tree for the graphical user interface (GUT) presented to the operator.

The Heat-Treatment Selection System is a feature of the software which permits the user to choose the temperature time profile suitable for any particular steel. It makes use of a stored Bohler Metals Database [10] containing details of temperature and time required for treating particular steels to specified hardness values. After entry of the specific parameters of the steel and hardness the system determines and executes the appropriate temperature-time profile to produce the required treatment.

Help Facilities are available to the user at many points in the menu structure, and in each case display hypertext pages (HTML files) with hyperlinks to associated information.

\section{Testing and Evaluation}

\subsection{Salt bath temperature measurements}

An assessment of the accuracy of the temperature measuring system for the salt baths was made by comparing the computer-displayed values of furnace temperature with the readings from a pyrometer directed at the liquid surface. In the first experiment the set-point was moved downward by $60^{\circ} \mathrm{C}$, from $1120^{\circ} \mathrm{C}$ to $1060^{\circ} \mathrm{C}$, and the resulting changes in readings over the twenty minute period are shown on the graph of Figure 6.

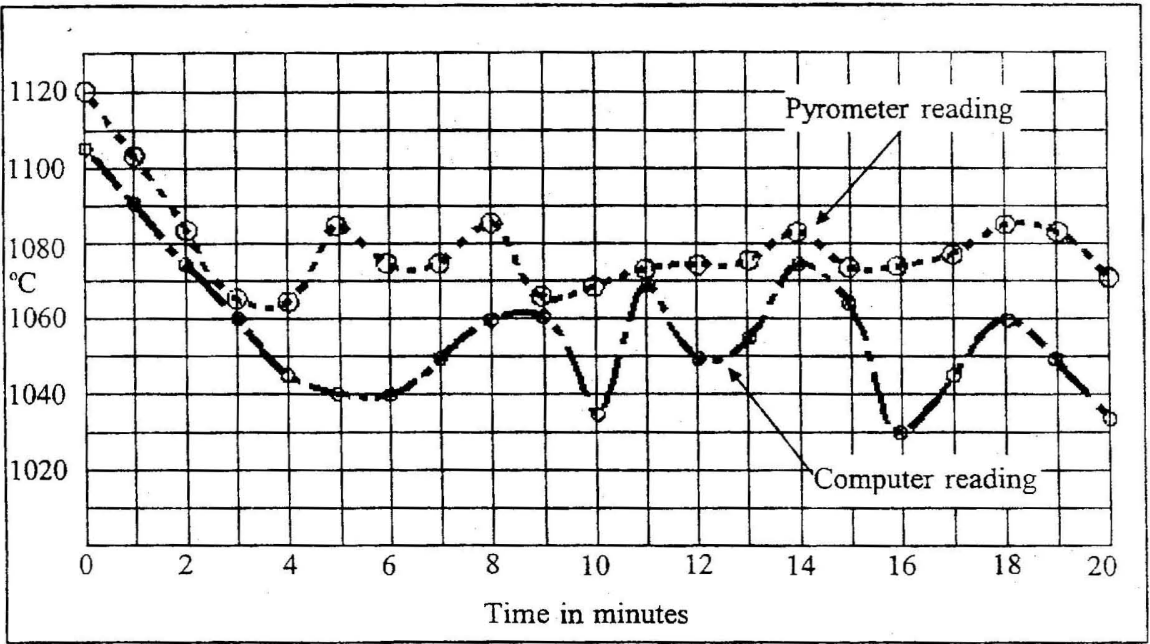

Figure 6: Temperature readings from salt bath while cooling

The differences between the two curves can be explained in a number of ways. It appears that there is a constant difference of about $15^{\circ} \mathrm{C}$ between the sets of readings, and this has been attributed to the fact that the emissivity of the salts in the furnace is not known to sufficient accuracy in calibrating the pyrometer. The increased swings of the computer 
readings compared with those of the pyrometer probably arise from the fact that the computer is reading the immersed thermocouple, and therefore detects the temperature overshoots as the heater is switched on and off. The thermal mass of the salt solution damps these temperature oscillations by the time they reached the surface. The overall results of the experiment indicate that the computer-controlled system appears to be giving a clear indication of thermal changes in the furnace.

A further experiment was performed in which the set-point was moved in the upward direction by a much greater amount. The change was $240^{\circ} \mathrm{C}$, from $940^{\circ} \mathrm{C}$ to $1180^{\circ} \mathrm{C}$, and measurements were made by the computer, the pyrometer and the original Commander 50 temperature indicator. The results over a ninety minute period are shown in Figure 7. Because of the much larger temperature change, the oscillatory effects shown in the previous experiment were not discernible, but a deviation of the computer value from the other two was observed, increasing with temperature. This deviation was within $5 \%$ over the range tested, which was considered to be adequate for heat treatment processes.

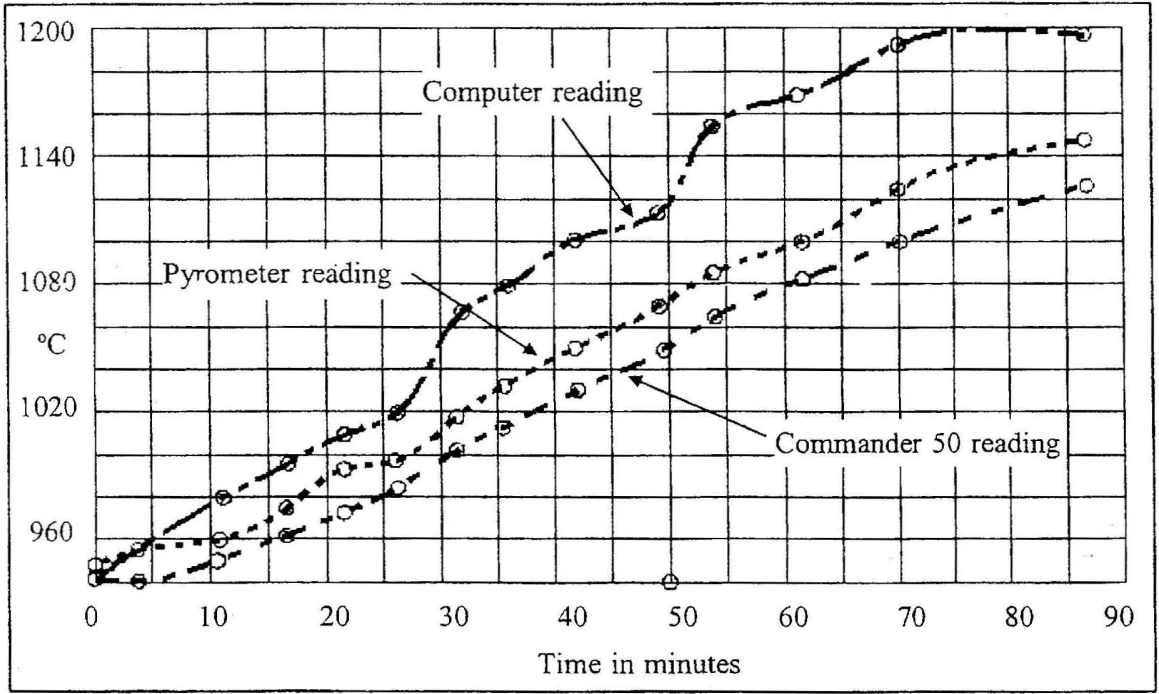

Figure 7: Temperature readings from salt bath while heating up

\subsection{Box oven temperature measurements}

Readings were taken while one of the box ovens was heating up over the range $350^{\circ} \mathrm{C}$ to $500^{\circ} \mathrm{C}$, comparing the values from the computer with those from a hand-held electronic thermometer. The results for the eighty minute period are shown in Figure 8 , from which it can be seen that once the temperature rose above $400^{\circ} \mathrm{C}$ the difference in readings remained constant at about $20^{\circ} \mathrm{C}$ which is $5 \%$ of the temperature. The probable explanation is that the hand-held thermometer was located at a different position from the computer-read thermocouple, and that a small temperature gradient across the oven caused the difference. 


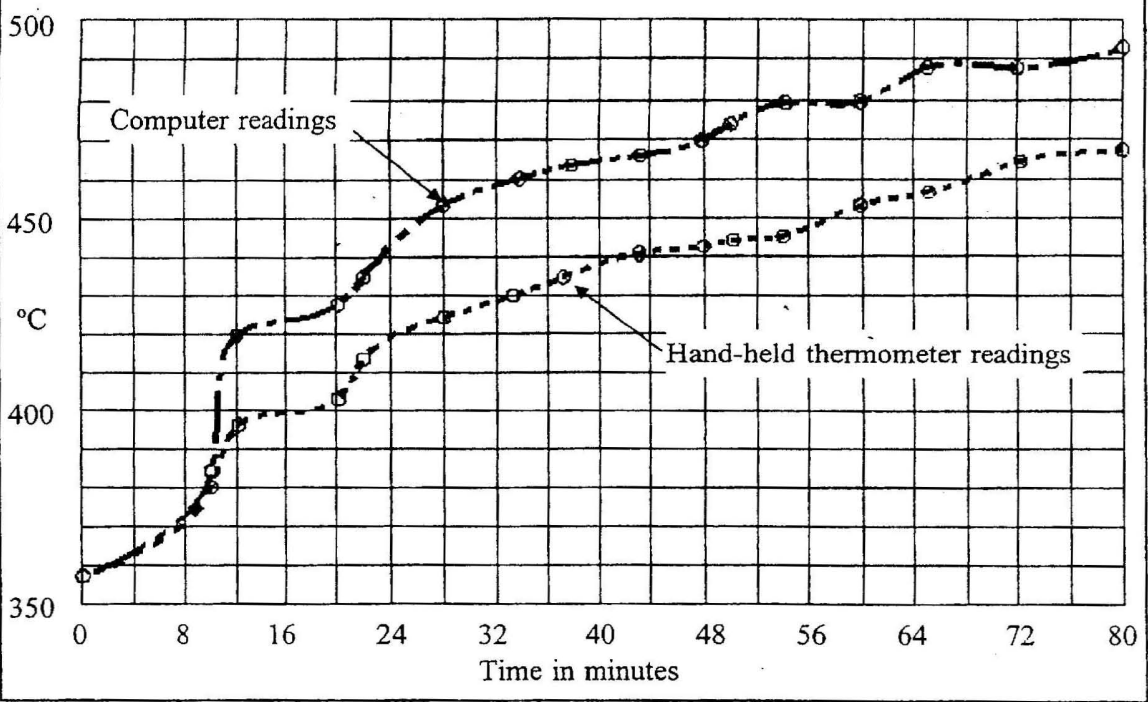

Figure 8: Temperature readings from the box oven

\subsection{Process results}

Following the concept of a "merit index" for process controllers suggested by Safiuddin [11] statistics were studied from the quality control department for the periods before and after the introduction of the computerized system. A summary of the number of items not conforming to specification because of warping or cracking during heat-treatment is given in Table 1. The computerized system was introduced in June 2000, and had run a full year at the time statistics were compiled.

\begin{tabular}{|c|c|}
\hline Year & $\begin{array}{c}\text { Number of non-conformance } \\
\text { items }\end{array}$ \\
\hline 1998 & 11 \\
\hline 1999 & 9 \\
\hline 2000 & 8 \\
\hline 2001 & 0 \\
\hline
\end{tabular}

Table 1: Quality control statistics

To ascertain the effectiveness of the system for a full heat-treatment process, a batch of wedge NUT bottom dies was treated at $1020^{\circ} \mathrm{C}$ to produce a specific hardness. The targeted Rockwell value was $52 \mathrm{HRC}$. Before tempering, the value was measured as $54 \mathrm{HRC}$, and after the tempering stage came out as $52 \mathrm{HRC}$.

\subsection{Corporate response}

The company has been sufficiently impressed with the results of the project to request the same team from the National University of Science and Technology to undertake the computerisation of other sections of the factory. The management is of the opinion that the 
system has been developed at a fraction of the cost of an imported system using overseas expertise.

The benefits which the company has identified from the new system are:-

1. Improved accountability, since the computer generates log files of all operations showing time and temperature. This allows the Hardening Shop supervisor to analyse the data files with a view to detecting inefficiencies or abuses.

2. Temperature display for all furnaces from the central control computer, being an improvement on the old analogue controllers which did not display actual readings.

3. Reactivation of one of the glow-bar furnaces which has been out of service with a faulty controller for a considerable period, since this can be connected directly into the new system.

4. Ability to enter a heat-treatment schedule into the computer, and leave the machine to control the entire process.

5. A prompting facility which instructs the operators when to enter or remove jobs from the furnaces and when to change set-points.

\section{Conclusion}

The term "appropriate technology" has sometimes been used pejoratively to imply a low level of design, reliability and maintenance in countries where the benefits of sophisticated engineering are not available. However, this project has shown that there can be advantages in utilising products whose origin is in the same country, where the designers may be only a phone-call away, and where maintenance can be obtained without the need to ship equipment across international borders. The appropriateness of a technological solution may be measured by the degree to which local expertise is married up with a local problem to improve efficiency and productivity.

The success of the project described in this paper is an indication of the availability of local engineering expertise within Zimbabwe, and provides a migration route for companies needing to enhance their production facilities to meet new technological and market demands. Rather than invest in a completely new control suite at heavy cost, the computerisation of the existing system has provided the same functionality within the economic constraints of the present national situation.

\section{References}

[1] Collier M., June 2001, "Utilising local technical expertise in Zimbabwe - a case study", The African Technologist, ISSN 1533-5186, Oakdale, U.S.A.

[2] Sibanda M. \& Collier M., May 2000, "The opportunities afforded by embedded control systems for monitoring and control of industrial processes in less-industrialised countries", Proc 4th Intl. Conf. on Manufacturing Processes, Systems and Operations Management in Less Industrialised Regions, Bulawayo.

[3] Mierzwinski E.P., 1991, "Integrated furnace control", IEEE Trans on Industrial Applications, Vol. 27, No. 2. 
[4] Intel, 1990, 8-bit Embedded Controllers, Mt. Prospect, U.S.A.

[5] Philips, 1999, Single-Chip 8-Bit Microcontrollers, Eindhoven.

[6] Siemens, 1991, 8-Bit Single-Chip Microcontroller Handbook, Santa Clara, U.S.A.

[7] Query D.S. \& Tescher G., 1990, "Advantages of microprocessors versus discrete digital electronics in appliance controls", IEEE Trans on Industrial Applications, Vol 26, No.6.

[8] Ayala K.J., 1991, The 8051 Microcontroller: Architecture, Programming and Applications, West Publishing Co., St Paul, U.S.A.

[9] Yeralan S. \& Ahluwalia A., 1995, Programming and Interfacing the 8051 Microcontroller, Rigel Corp., U.S.A.

[10] Bohler Stocklist, Bohler Steel Africa, Tiger Press, Johannesburg.

[11] Safiuddin M. \& Markiewicz G.A., 1990, "A case study on the selection of performance index for design optimization of new controllers", IEEE Trans on Industrial Applications, Vol. 26, No. 4. 